Agr. Biol. Chem., 40 (7), 1273 1277, 1976

\title{
Thermodynamics of the Temperature-dependent Denaturation of $\alpha$-Lactalbumin
}

\author{
Kenji TAKase, Ryoya NiKI and Shunrokuro ARIMA \\ Institute of Dairy Science, Faculty of Agriculture, \\ Hokkaido University, Kita-ku, Sapporo \\ Received November 7, 1975
}

\begin{abstract}
The proposed similarity of conformation between $\alpha$-lactalbumin ( $\alpha$-LA) and hen egg-white lysozyme was tested by the comparison of the thermodynamic parameters obtained from the temperature dependence of denaturation. For the denaturing reaction by guanidine hydrochloride, the value of $\Delta C_{p}$ for $\alpha$-LA is almost identical with that for lysozyme, which suggests that the amount of the hydrophobic side chains buried in the interior of the molecule is the same in the native state; the value of $\lrcorner H^{\circ}$ and $J S^{\circ}$ for a-LA are also close to those for lysozyme, and the small differences are explicable by the proposed molecular model of $\alpha-\mathrm{LA}$, which implies that the somewhat large difference in $\Delta G^{\circ}$ observed previously between the two proteins does not originate from large conformational differences. These results support the conformational similarity between $\alpha$-LA and lysozyme as represented by the molecular model. The heat-denatured state of $\alpha-\mathrm{LA}$ is also characterized by the parameters and discussed.
\end{abstract}

A milk protein, $\alpha-\mathrm{LA}^{* 1}$ is one of the subunits of lactose synthetase. ${ }^{11}$ Its function is very unique in that $a$-LA modifies the substrate (acceptor) specificity of the other subunit, galactosyltransferase from $\mathrm{N}$-acetyl-Dglucosamine to glucose by unknown interactions between the subunits, though $\alpha$-LA only slightly inhibits the transfer of galactose to the carbohydrate side chains of glycoproteins which have terminal nonreducing $\mathrm{N}$-acetylglucosaminyl residues. ${ }^{23}$ On the other hand, the amino acid sequence ${ }^{3}$ and the disulphide bridge arrangement ${ }^{4}$ of $\alpha$-LA is strikingly similar to that of hen egg-white lysozyme, which has led Browne et al. ${ }^{5}$ to consider that the molecular conformations of the two proteins may be very similar and to build a model of the $\alpha$-LA molecule based on the known three-dimensional structure of hen egg-white lysozyme. $\left.{ }^{6}\right)$ Although the subsequent experiments made by many workers support the model, more works are needed in order to elucidate the conformation of $\alpha-\mathrm{LA}$.

As a basis for understanding the nature of the interactions between the subunits of lactose synthetase and the mechanism of lactose synthesis, we have been studying the confor- mation of $\alpha$-LA mainly by comparing its physico-chemical properties with those of lysozyme and thereby testing the molecular model of $\alpha$-LA. Our previous papers ${ }^{7,8)}$ concerned the isothermal denaturation of $\alpha$-LA by $\mathrm{GuHCl}^{* 2}$ and guanidine thiocyanate, and demonstrated that there are somewhat large differences in such as the free energy of stabilization of the native state against the disordered state between $\alpha$-LA and lysozyme. These differences led us to evaluate other thermodynamic parameters which relate closely to conformation by studying the effect of temperature on denaturation and to examine the similarity of conformation and the origin of the free energy difference between $\alpha$-LA and lysozyme.

\section{MATERIALS AND METHODS}

$\alpha-L A . \quad \alpha-\mathrm{LA}$ was prepared from fresh unpasteurized bovine milk by the method of Cervone et $a l .^{9\rangle}$ except that DEAE-Sephadex A-50 was used instead of DEAE-cellulose. The ultraviolet spectra and the behavior of the denaturation by $\mathrm{GuHCl}$ coincided well with the previous results. ${ }^{1,7)}$ Stock solutions of $\alpha-$ LA,

*1 $\quad \alpha$-LA: $\alpha$-lactalbumin.

*2 GuHCl: guanidine hydrochloride. 
dissolved in $0.1 \mathrm{M}$ sodium phosphate buffer or in distilled water, were filtered through a membrane filter with a pore radius of $0.45 \mu \mathrm{m}$. The protein concentration was determined by absorption measurements at $280 \mathrm{~nm}$ using an extinction coefficient of $E_{1 \mathrm{~cm}}^{1 \%}=$ $20.1,^{10)}$ and a molecular weight of $14,200^{3)}$ was used for calculating molar quantities.

Reagents. GuHCl was purchased from Nakarai Chemical Co. (specially prepared reagent for biochemical research). The $\mathrm{GuHCl}$ concentration was determined by measuring the refractive index at $589 \mathrm{~nm}$. ${ }^{11}$ )

Difference spectra. A Hitachi recording spectrophotometer, type EPS-3T, equipped with thermostatically controlled cell holders with the precision of $\pm 0.1^{\circ} \mathrm{C}$ was employed. The reference cell was kept at $25^{\circ} \mathrm{C}$, while the sample cell was brought to various temperatures The temperature of the solution in the cell was determined with a thermistor. Thermal equilibration was complete in $10 \mathrm{~min}$. The protein concentration was usually $30 \sim 40 \mathrm{mg} / \mathrm{dl}$. In order to correct the small absorption of $\mathrm{GuHCl}$, two pairs of $1 \mathrm{-cm}$ square cells were used for the protein solutions and $\mathrm{GuHCl}$ solution. In addition to visual checks on turbidity, each set of solutions was examined during the course of the measurements at $330 \sim 350 \mathrm{~nm}$ where absorption was considered to be absent.

\section{RESULTS}

Thermal denaturation in the presence of $\mathrm{GuHCl}$

The thermal difference spectra with a reference in $0.1 \mathrm{M}$ sodium phosphate buffer $(\mathrm{pH}$ $6.8,25^{\circ} \mathrm{C}$ ) showed major peaks at 285 and $292 \mathrm{~nm}$ characteristic of tryptophanyl residues, and the intensity at $292 \mathrm{~nm}$ at several $\mathrm{GuHCl}$ concentrations is shown as a function of temperature in Fig. 1. The reaction seems to be rapid and no time dependency was observed for several hours. The thermodynamic reversibility was demonstrated as shown in Fig. 1. The curves at intermediate concentrations of $\mathrm{GuHCl}$ peak at near $18^{\circ} \mathrm{C}$, indicating maximum stability at that temperature. The apparent equilibrium constant for the reaction $\mathrm{N} \rightleftarrows \mathrm{D}$ ( $\mathrm{N}$ : the native state, $\mathrm{D}$ : the denatured state obtained by the action of $\mathrm{GuHCl}$ ) was calculated from these data as

$$
K_{\mathrm{spp}}=\left(\Delta E-\Delta E_{\mathrm{N}}\right) /\left(\Delta E_{\mathrm{D}}-\Delta E\right)
$$

where $\Delta E$ is the observed molar absorption difference and $\Delta E_{\mathrm{N}}$ and $\Delta E_{\mathrm{D}}$ represent the

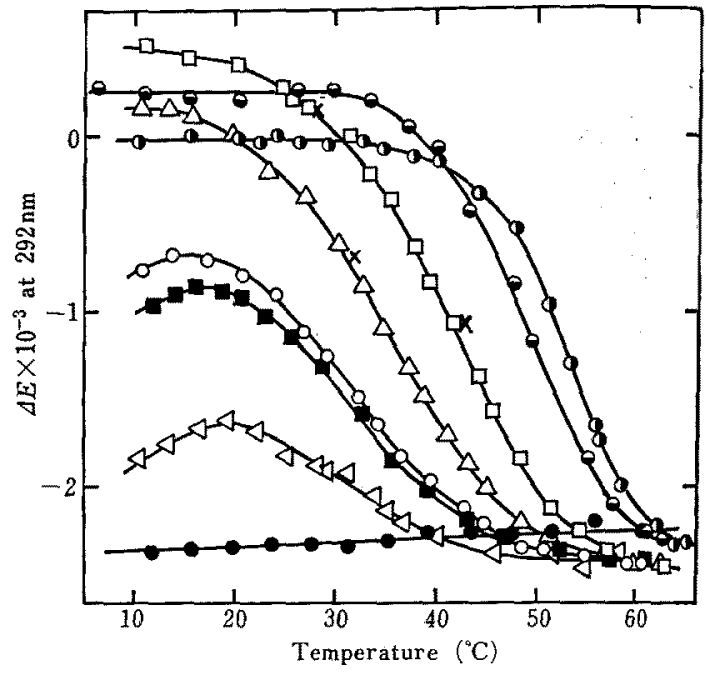

FIG. 1. Difference Spectral Intensity at $292 \mathrm{~nm}$ as a Function of Temperature under Various Conditions. All solutions contained $0.1 \mathrm{M}$ sodium phosphate buffer. The crosses represent reversals from high temperature.

๑, 0 м GuHCl, pH 6.80;, 0.55 м GuHCl, pH 6.36; $\square, 1.21 \mathrm{M} \mathrm{GuHCl}, \mathrm{pH} 6.00 ; \triangle, 1.63 \mathrm{M} \mathrm{GuHCl}, \mathrm{pH} 5.86 ;$ $0,1.93 \mathrm{M} \mathrm{GuHCl}, \mathrm{pH} 5.78 ; \mathbf{m}, 2.06 \mathrm{M} \mathrm{GuHCl}$, pH5.75; $\triangleleft, 2.23 \mathrm{M} \mathrm{GuHCl}, \mathrm{pH} 5.72 ; 0,5.97 \mathrm{M} \mathrm{GuHCl}, \mathrm{pH} 5.17$.

differences which the states $\mathrm{N}$ and $\mathrm{D}$ would have under the same condition, respectively. The values of $\Delta E_{\mathrm{N}}$ and $\Delta E_{\mathrm{D}}$ were obtained by correcting the dependence on $\mathrm{GuHCl}$ concentration at $25^{\circ} \mathrm{C}$ for the slight dependence on temperature. In Fig. 2 are shown the Van't

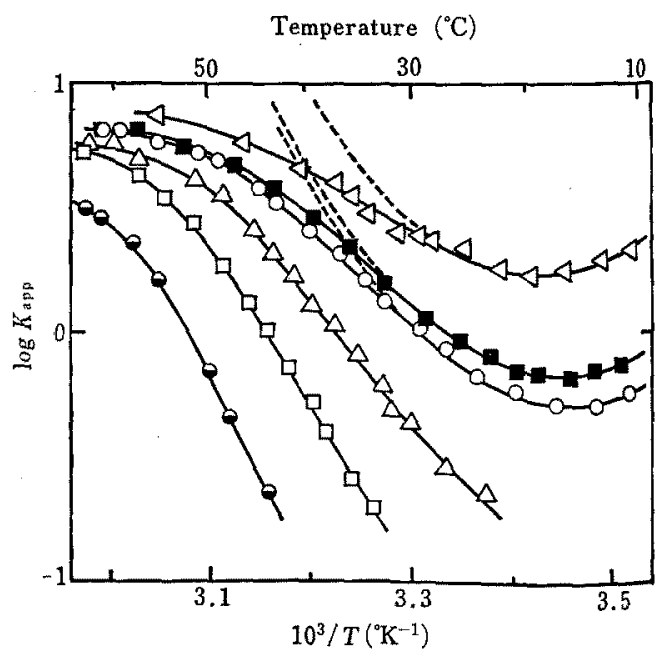

Fig. 2. Van't Hoff Plots of the Data of Fig. 1.

The symbols have the same meaning as in Fig. 1. The dashed lines are theoretical for the two-state trancition at higher temnerature. 
Hoff plots. It has been previously shown ${ }^{12,13}$ \} that the heat-denatured state $(\mathrm{X})$ obtained by raising the temperature in the absence of $\mathrm{GuHCl}$ differs from the state $\mathrm{D}$, and that the state $X$ contributes to the equilibrium $N \rightleftarrows D$ significantly at high temperature even in the presence of $\mathrm{GuHCl}$. The present data show a similar case: the absolute values of $\Delta E$ at high temperature except $5.97 \mathrm{M} \mathrm{GuHCl}$ are considerably smaller than those expected when completely denatured by $\mathrm{GuHCl}$, i.e., $\Delta E_{\mathrm{D}}$ (see Fig. 1, e.g., $\Delta E_{\mathrm{D}}$ at $2 \mathrm{M} \mathrm{GuHCl}=$ $\left.2970 \mathrm{M}^{-1} \cdot \mathrm{cm}^{-1}\right)$; the slope of the curves of Fig. 2 varies with temperature just as predicted when stable intermediates exist and the two-state theory cannot be applied above $30^{\circ} \mathrm{C}$. Therefore we evaluated the thermodynamic parameters assuming the equilibrium $\mathrm{N} \rightleftarrows \mathrm{D}$ below $30^{\circ} \mathrm{C}$ and $\mathrm{N} \rightleftarrows \mathrm{X} \rightleftarrows \mathrm{D}$ above that temperature and using the following equations $^{141}$

$$
\begin{gathered}
K_{\mathrm{app}}=\frac{K_{\mathrm{D}}+\alpha K_{\mathrm{NX}}}{1+(1-\alpha) K_{\mathrm{NX}}} \\
\alpha=\left(\Delta E_{\mathrm{X}}-\Delta E_{\mathrm{N}}\right) /\left(\Delta E_{\mathrm{D}}-\Delta E_{\mathrm{N}}\right)
\end{gathered}
$$

where $K_{\mathrm{D}}$ and $K_{\mathrm{Nx}}$ are the equilibrium constants for the reaction $\mathrm{N} \rightleftarrows \mathrm{D}$ and $\mathrm{N} \rightleftarrows \mathrm{X}$, respectively, $*$ and $\Delta E_{\mathrm{X}}$ is $\Delta E$ in the state $\mathrm{X}$. The value of $\alpha$ was calculated to be 0.75 from Eq. 2, the value of $\Delta E_{\mathrm{x}}$ being taken from the limiting value at high temperature in the heat- parable to those for other proteins. Below $30^{\circ} \mathrm{C} K_{\mathrm{D}}=K_{\mathrm{app}}$, and the temperature dependence of $K_{\mathrm{D}}$ gives $\Delta H_{\mathrm{D}}^{\circ}$ and that of $\Delta H_{\mathrm{D}}^{\circ}$ gives $\Delta C_{p, \mathrm{D}}$ directly. Above $30^{\circ} \mathrm{C} K_{\mathrm{Nx}}$ can be calculated from Eq. 1 by using $K_{\mathrm{D}}$ values extrapolated from those below $30^{\circ} \mathrm{C}$ by use of a $\Delta C_{p, \mathrm{D}}$ value, and the temperature dependence of $K_{\mathrm{NX}}$ gives $\Delta H_{\mathrm{NX}}^{\circ}$, but $\Delta C_{\mathrm{p}, \mathrm{NX}}$ could not be accurately determined and was taken as $\alpha$. $\Delta C_{p, \mathrm{D}} . \quad \Delta S^{\circ}$ was calculated from $\Delta H^{\circ}$ and $\Delta G^{\circ}$ $\Delta G^{\circ}$ at low $\mathrm{GuHCl}$ concentration was calculated by the equation obtained previously." The parameters thus obtained are summarized in Table I along with corresponding data for lysozyme. ${ }^{13)}$

\section{Thermal denaturation in the absence of $\mathrm{GuHCl}$}

Figure 3 shows the thermal denaturation in the absence of $\mathrm{GuHCl}$ at various $\mathrm{pH}$ and in the presence of $\mathrm{Mn}^{2+}$ which is necessary for the activity of lactose synthetase. It is seen that shifts in $\mathrm{pH}$ between 5.21 and 6.80 and the addition of $2.5 \mathrm{~mm}$ manganese chloride has no effects on the stability, whereas pH 4.42 has a destabilizing effect. The analysis of the data assuming a two-state transition from the state $\mathrm{N}$ to $\mathrm{X}$ gave the following results: at $52.5^{\circ} \mathrm{C}, \Delta H_{\mathrm{N} X}^{\circ}=51 \pm 2 \mathrm{kcal} / \mathrm{mole}$ for all data (i.e., independent of $\mathrm{pH}$ ), $\Delta S_{\mathrm{NX}}^{\mathrm{o}}=157 \mathrm{kcal} /$ $\mathrm{deg} /$ mole except $\mathrm{pH} 4.42$, and the value of $1 \mathrm{kcal} / \mathrm{deg} / \mathrm{mole}$ for $\Delta C_{p, \mathrm{~N}}$ obtained in the

\begin{tabular}{|c|c|c|c|c|c|c|c|}
\hline \multirow{2}{*}{$\frac{\text { Reaction }}{\mathrm{N} \rightleftarrows \mathrm{D}}$} & $\begin{array}{c}\Delta G^{\circ} \\
(\mathrm{kcal} / \mathrm{mole})\end{array}$ & \multicolumn{2}{|c|}{$\begin{array}{c}\Delta H^{\circ b} \\
(\mathrm{kcal} / \mathrm{mole})\end{array}$} & \multicolumn{2}{|c|}{$\begin{array}{c}\Delta S^{\circ} \\
\text { (cal } / \mathrm{deg} / \text { mole) }\end{array}$} & \multicolumn{2}{|c|}{$\begin{array}{c}\Delta C_{p} \\
\text { (cal/deg/mole) }\end{array}$} \\
\hline & $2.8^{7)} \quad(7.9)$ & 11 & (22) & 28 & $(49)$ & 1350 & (1375) \\
\hline$N \rightarrow X$ & $2.1^{6)}(7.8)$ & $19^{d 2}$ & (41) & 58 & (112) & $1000^{\circ)}$ & $(950)$ \\
\hline 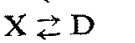 & $0.7 \quad(0.1)$ & -8 & $(-19)$ & -30 & $(-63)$ & 350 & $(425)$ \\
\hline
\end{tabular}

Table I. Thermodynamic Parameters in $1 \mathrm{M} \mathrm{GuHCl}, 25^{\circ} \mathrm{C}$, pH $7^{a}$ )

a) Determined from the three heating curves at ca. $2 \mathrm{M} \mathrm{GuHCl}$. The values in parentheses are for lysozyme. ${ }^{13)}$

b) Assumed to be independent of $\mathrm{GuHCl}$ concentration and $\mathrm{pH}$.

c) Estimated by the procedure described by Tanford et al. ${ }^{13)}$

d) An extrapolated value from high temperature using a value of $\Delta C_{p}$.

ing curves in the absence of $\mathrm{GuHCl}$ as shown in Fig. 3. The obtained value of $\alpha$ is com-

* The subscripts $\mathrm{D}, \mathrm{NX}$, and $\mathrm{XD}$ denote the reaction $\mathrm{N} \rightleftarrows \mathrm{D}, \mathrm{N} \rightarrow \mathrm{X}$, and $\mathrm{X} \leftrightarrow \mathrm{D}$, respectively. preceding paragraph fitted well. It should be noted that the above values coincide well with those obtained by the analysis of the data in the presence of $\mathrm{GuHCl}\left(\Delta H_{\mathrm{NX}}^{\circ}=46 \mathrm{kcal}\right)$ 


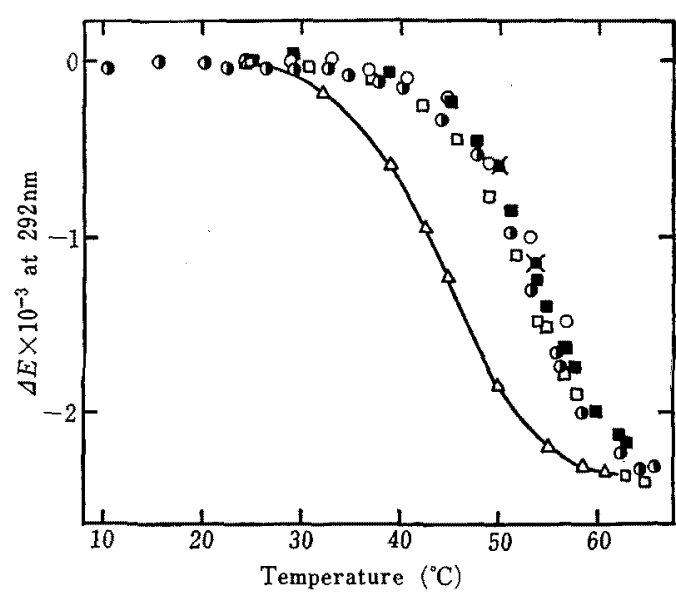

F1G. 3. Thermal Denaturation in the Absence of $\mathrm{GuHCl}$ at Various pH Values, as Followed by Difference Spectral Measurements at $292 \mathrm{~nm}$.

All solutions contained $0.1 \mathrm{M}$ buffer (sodium phosphate, sodium acetate). The crosses represent reversals from high temperature.

(, pH $6.80 ; \mathrm{O}$, pH $5.97 ; \square$, pH $5.21 ; \mathbf{\square}$, pH $5.21+$ $2.5 \mathrm{~mm} \mathrm{MnCl}_{2} ; \triangle, \mathrm{pH} 4.42$.

mole, $\Delta S_{\mathrm{NX}}^{\circ}=141 \mathrm{kcal} / \mathrm{deg} / \mathrm{mole}$ at $52.5^{\circ} \mathrm{C}$ ), which would indicate the validity of the theoretical treatment of the data.

\section{DISCUSSION}

We obtained the thermodynamic parameters of the denaturation of $\alpha$-LA from the effect of temperature on denaturation (Table I). The validity of the parameters was demonstrated by showing the good agreement of the values obtained from the analysis in the presence of $\mathrm{GuHCl}$ with that in the absence of $\mathrm{GuHCl}$. It is evident from Table $I$ that the value of $\Delta C_{p, \mathrm{D}}$ for $\alpha$-LA coincides well with that for lysozyme and that the differences in $\Delta H_{\mathrm{D}}^{\circ}$ and $\Delta S_{\mathrm{D}}^{\circ}$ between the two proteins are small. (At $25^{\circ} \mathrm{C}, \Delta H^{\circ}$ and $\Delta S^{\circ}$ values ranging from -21 to $+47 \mathrm{kcal} / \mathrm{mole}$ and from -72 to $+105 \mathrm{cal} / \mathrm{deg} / \mathrm{mole}$, respectively have been reported for various proteins.) The agreement of the values of $\Delta C_{p, \mathrm{D}}$ for the two proteins suggests that the amount of the hydrophobic side chains buried in the interior of the molecule is the same in the native state, since a major contribution to $\Delta C_{p}$ is supposed to be made by the exposure of such groups to the aqueous solvent medium. ${ }^{14,15\rangle} \quad \Delta H^{\circ}$ and $\Delta S^{\circ}$ depend on details of the native conformation and the number and strength of internal bonds that are broken, ${ }^{14,15}$ ) so the small differences in the values may suggest that there are only small differences in conformation between $\alpha$-LA and lysozyme. In the following paragraph we attempted to interpret these differences by the molecular model of $\alpha-\mathrm{LA}$ proposed by Browne et al., ${ }^{51}$ which resembles the conformation of lysozyme and by the experimental results of other investigators.

Assuming that the differences in $\Delta H^{\circ}$ and $\Delta S^{\circ}$ between $\alpha$-LA and lysozyme shown in Table $I$ are due to the differences in the numbers of hydrogen bonds and/or hydrophobic bonds, we determined the differences in such numbers $(a, b)$ involved in each reaction by solving the following equations

$$
\begin{aligned}
& \left.\Delta H^{\circ}(\alpha-\mathrm{LA})=\Delta H^{\circ} \text { (lysozyme }\right)+\Delta h_{\mathrm{H}} \cdot \mathrm{a} \\
& \quad+\Delta h_{\mathrm{H} \phi} \cdot \mathrm{b} \\
& \Delta S^{\circ}(\alpha-\mathrm{LA})=\Delta S^{\circ}(\text { lysozyme })+\Delta s_{\mathrm{H}} \cdot \mathrm{a} \\
& \quad+\Delta s_{\mathrm{H} \phi} \cdot \mathrm{b}
\end{aligned}
$$

where $\Delta h_{\mathrm{H}}$ and $\Delta h_{\mathrm{H} \phi}$ are the enthalpy change for breaking a single hydrogen bond and hydrophobic bond in the interior of the molecule and then exposing to the solvent, respectively, and $\Delta s_{\mathrm{H}}$ and $\Delta s_{\mathrm{H} \phi}$ are the entropy changes for such processes, and average of the values reported previously ${ }^{15,16)}$ were used: $\Delta h_{\mathrm{H}}=1 \mathrm{kcal} / \mathrm{mole}, \Delta s_{\mathrm{H}}=3$ e.u.; $\Delta h_{\mathrm{H} \phi}=-2$ $\mathrm{kcal} / \mathrm{mole}, \Delta s_{\mathrm{H} \phi}=-15$ e.u. The result is shown in Table II as given by the differences

TABle II. Differences IN The Numbers of Hydrogen Bonds AND HydRophobIC Bonds BETWEEN $\alpha$-LACTALBUMIN AND LYSOZYME ${ }^{a}$ )

\begin{tabular}{lrr}
\hline \multicolumn{1}{c}{ State } & $\mathrm{N}$ & $\mathrm{X}$ \\
\hline Hydrogen bond & -14 & +11 \\
Hydrophobic bond & -1 & 0 \\
\hline
\end{tabular}

a) The sign + denotes that $\alpha$-lactalbumin has more such bonds than lysozyme. The state $\mathrm{D}$ is assumed to have no bonds.

in the numbers in each state. Takesada et $a l .{ }^{17)}$ showed by the hydrogen-deuterium exchange experiment that native lysozyme 
has nine more hydrogen bonds than native a-LA. Detailed examination of the molecular model also led them to the same conclusion. Our result in Table II agrees well with their conclusion for the assumption made in our calculation. According to the model, a few hydrophobic residues in the interior of the lysozyme molecule are replaced by hydrophilic residues or located on the surface of the molecule in $\alpha-\mathrm{LA}$, so that it is likely that the number of hydrophobic bonds is a little less in $\alpha$-LA than in lysozyme. The present result that there is only one difference in the number of such bonds between them in the native state agrees with the above consideration and also corresponds to the agreement of $\Delta C_{p, D}$. As for the heat-denatured state, $\alpha$-LA has more hydrogen bonds than lysozyme according to our result, which again agrees with the results of circular dichroism measurements $^{17}$ ) that the heat-denatured state of $a-\mathrm{LA}$ has an appreciable amount of folded structures as compared with that of lysozyme. Thus, the differences in $\Delta H^{\circ}$ and $\Delta S^{\circ}$ between $a-L A$ and lysozyme can reasonably be explained by the molecular model and other experimental results. This supports the conformational similarity between $\alpha$-L.A and lysozyme as represented by the molecular model.

Our previous papers ${ }^{7,8}$ showed that there exists a somewhat large difference in $\Delta G_{\mathrm{D}}^{\mathrm{b}}$ between $\alpha$-LA and lysozyme (Table I), corresponding to a large difference in the stability against $\mathrm{GuHCl}, \mathrm{pH}$, and heat; however the significance of this difference was not clarified. The present result that there are only small differences in $\Delta H_{\mathrm{D}}^{\circ}$ and $\Delta S_{\mathrm{D}}^{\circ}$ between $\alpha$-LA and lysozyme and that the differences are explicable by the molecular model implies that the somewhat large difference in $\Delta G_{\mathrm{D}}^{\mathrm{D}}$ is also explicable by the model, i.e., the difference does not originate from large conformational differences between $\alpha$-LA and lysozyme.

\section{REFERENCES}

1) U. Brodbeck, W. L. Denton, N. Tanahashi and K. E. Ebner, J. Biol. Chem., 242, 1391 (1967).

2) K. E. Ebner and F. L. Schanbacher, "Lactation," Vol. II, ed. by B. L. Larson and V. R. Smith, Academic Press Inc., New York and London, 1974, p. 77.

3) K. Brew, F. J. Castellino, T. C. Vanaman and R. L. Hill, J. Biol. Chem., 245, 4570 (1970).

4) T. C. Vanaman, K. Brew and R. L. Hill, ibid., 245, 4583 (1970).

5) W. J. Browne, A. C. T. North D. C. Phillips, K. Brew, T. C. Vanaman and R. L. Hill, J. Mol. Biol., 42, 65 (1969).

6) C. C. F. Blake, G. A. Mair, A. C. T. North, D. C. Phillips and V. R. Sarma, Proc. Roy. Soc., B,167, 365 (1967).

7) S. Sugai, H. Yashiro and K. Nitta, Biochim. Biophys. Acta, 328, 35 (1973).

8) K. Takase, K. Nitta and S. Sugai ibid., 371, 352 (1974).

9) F. Cervone, J. D. Brito, G. D. Prisco, F. Garofano, L. G. Noroña, S. Traniello and R. Zito, ibid., 295, 555 (1973).

10) M. J. Kronman and R. E. Andreotti, Biochemistry, 3, 1145 (1964).

11) Y. Nozaki, "Methods in Enzymology," Vol. XXVI, ed. by C. H. W. Hirs and S. N. Timashef, Academic Press Inc., New York and London, 1972 , p. 43.

12) K. C. Aune, A. Salahuddin, M. H. Zarlengo and C. Tanford, J. Biol. Chem., 242, 4486 (1967).

13) C. Tanford and K. C. Aune, Biochemistry, 9, 206 (1970).

14) C. Tanford, "Advances in Protein Chemistry," Vol. XXIII, ed. by C. B. Anfinsen, Jr., J. T. Edsall, M.L. Anson and F. M. Richards, Academic Press Inc., New York and London, 1968, p. 121.

15) C. Tanford, ibid., Vol. XXIV, 1970, p. 1.

16) G. Némethy, Angew. Chem. internat. Edit., 6, 195 (1967).

17) H. Takesada, M. Nakanishi, and M. Tsuboi, $J$. Mol. Biol., 77, 605 (1973). 